TP Periodica Polytechnica Architecture

47(1), pp. 14-29, 2016

DOI: 10.3311/PPar.9477

Creative Commons Attribution (i)

RESEARCH ARTICLE

\section{Thermal Models for Box Type Windows: Part 1}

\author{
Dániel Bakonyi $1^{*}$, Gergely Dobszay ${ }^{1}$
}

Received 13 May 2016; accepted after revision 19 July 2016

\begin{abstract}
Techniques for the thermal modelling of contemporary single skin windows with insulating glass units are well developed, but their applicability for traditional box type windows is under investigated. Due to their different construction and dimensions, a different type of natural convection is encountered in their air cavity. In this article, a literature review is conducted to analyse the characteristics of this flow and its difference from the flows in contemporary windows. Finally, the best-known correlations used to quantify the convective heat transfer in glazing cavities are analysed with regards to their validity for the specific case of box type windows.
\end{abstract}

\section{Keywords}

historical double skin window, box type window, heat loss calculation, convection in glazing cavity, natural convection

\section{Introduction}

The thermal and solar/optical properties of windows can either be determined by measurement or by calculation. The required measurements (e.g. Hot-Box measurement for the U-value, and integrating-sphere measurement for the solar transmission of glazing layers) are very expensive and timeconsuming to perform. The wide variety of possible geometries that can be assembled from a single window profile type and glazing system, shows that it would require a huge number of these measurements to be performed to provide designers with a usable database. This makes laboratory measurements impractical as an aid for the everyday practice of fenestration thermal design. A great deal of effort was invested instead in developing databases, calculation methods, standards and software to enable accurate prediction of fenestration thermal and optical performance indices from plans only. Measurements are usually only performed to aid the development of said methods, during the development of radically different new fenestration products and to perform an occasional validation of standard calculations.

The thermal properties of fenestration are harder to determine than most other parts of the external thermal envelope for three main reasons: their inherent inhomogeneity (different materials of frames, sashes, and spacers for example) their incorporation of transparent components (glazing), and the presence of gas-filled cavities (glazing and frame cavities) in their construction. Conductive, convective and radiative heat transfer processes are all important in determining their thermal performance. Calculation methods use a series of implicit assumptions and simplifications to make the task manageable; these rest on the common physical properties of most contemporary window constructions. Most contemporary windows are constructed as a single-skin or single layer framework with fixed and/or operable sashes that hold relatively thin (ca. 10 $40[\mathrm{~mm}])$ hermetically sealed multipane insulating glass units or opaque insulated panels of similar dimensions. IG units are completely self-contained and interface with the frame and sash elements only at a narrow section around their perimeter: the edge-of-glass area. The thermal interaction between 
glazing and frame and the effect of the spacer bars in the IG unit is limited to this area, and the processes within the glazing (convection and thermal radiation) itself are well approximated with one-dimensional models. Based on these properties, calculations are usually done in three major steps: calculation of centre-of-glazing values with one-dimensional models, calculation of multi-dimensional and frame effects on window/frame components (usually with $2 \mathrm{D}$ thermal simulations) where the glazing is approximated with effective material properties calculated in step one, and finally the combination of glazing and frame component results into whole-window characteristics with simple equations. These steps should provide approximate, but sufficiently accurate results, thus eliminating the need to perform much more involved three-dimensional simulations of conjugate heat transfer (coupled convective, conductive and radiative heat transfer).

The calculation methods developed based on this framework are laid down in a series of European, international and American standards. Standards describing centre-of-glazing thermal calculations are the European EN 673 (2011), the international ISO 10292 (1994) and ISO 15099 (2003), with the last being the most accurate and the one used in most North American calculations as well. The simulation of component level heat transfer is according to either the European EN 10077-2 (2012) or the American NFRC 100-2010 (2010) standards. The summation of the component heat transfer rates into a single window U-value follows either the European method in EN 10077-1 (2006) or the North American in NFRC 100-2010 (2010). The ISO 15099 (2003) standard contains both of these methods.

The solar-optical characteristics of glazing systems with only specular layers are calculated according to either EN 410 (2011) or ISO 9050 (2003), which both yield very similar results. The presence of non-specular layers, such as various shading devices, necessitate the use of more complex algorithms, such as ray-tracing or the matrix layer method of Klems (1993; 1994) using Bi-Directional Scattering Distribution Functions. European standards and calculation usually use the $\mathrm{g}$ value which is defined as a characteristic of the glazing only, while the SHGC value most commonly used in North America contains the inward flowing portion of the solar gain absorbed by the frame as well. European and American standards also pose different boundary conditions (ambient temperatures and incident solar radiation, etc.) on the calculation of these values.

Blanusa et al. (2007) have performed a comparison of the European (EN 673/EN 10077-1/2) and American calculation methods (ISO 15099, NFRC-100) for the same boundary conditions and found that neither one is clearly more accurate than the other in predicting multi-dimensional frame heat transfer. The small inherent discrepancies between the two models exist because they both try to approximate three-dimensional heat transfer processes (conduction, convection and radiation) with only two-dimensional calculations but in slightly different ways, and they pose different boundary conditions. These differences only grow larger when the glazing to frame area ratio is small, and three-dimensional effects become more dominant. To address this issue Kumar (2010) compared two and three-dimensional thermal calculations of window heat transfer and found no significant errors between them, while Gustavsen et al. (2008) compared hot-box measurements with calculations according to both methods and found errors of less than $10 \%$ for contemporary energy-efficient windows. Both Kumar and Gustavsen have indicated that two-dimensional calculations give window-level results that are acceptable, but component-level results and temperature fields can show significant errors due to the three-dimensional and convective effects that seem to cancel out at only at the whole window level. This compromise is generally acceptable if only the overall heat transfer values are of interest.

All of the models mentioned thus far were developed for contemporary single-skin windows with IG units and all of the recent cross comparison and validation effort presented here concentrated on such constructions. However, most of the historical windows in central Europe from the middle of the $19^{\text {th }}$ century to the middle of the $20^{\text {th }}$ century have a completely different construction. They are double skinned so called box type windows (Kastenfenster in German): they have two layers of wooden sashes, each with a single pane of glass. A 10-20 cm thick casing connects the exterior and interior frames forming an air layer between the glazing panes to provide additional thermal resistance. This construction was the end product of centuries of window development, and it represented an enormous leap forward in thermal comfort and insulation from previous windows that had only a single piece of glass separating the interior from the exterior environment. Many different subvarieties of such windows exist, which are characteristic of the country or region and in some cases, even for the decade of the building's construction. The two layers of sashes may both open towards the inside, or in an opposite direction, but the essential constructional principle and the high quality of craftsmanship that went into their making is the same.

As a result of this constructional difference, the main glazing cavity of box type windows is not sealed like in an IG unit, and it is formed not by small spacer bars but with the distance between two layers of sashes. The thickness of the cavity is much bigger; its height to width ratio much smaller, and it is flanked by the frame itself. This puts at least some of the simplifications in contemporary calculation methods in question. The different cavity dimensions will result in a type of natural convection significantly different from the one in IG units, one which is not well described by one-dimensional models and effective material properties. Additionally, the interaction between the convective and radiative heat transfer in the cavity and conduction in the solid bodies of the frame is made much more pronounced (see also in Bakonyi and Becker (2014)). 

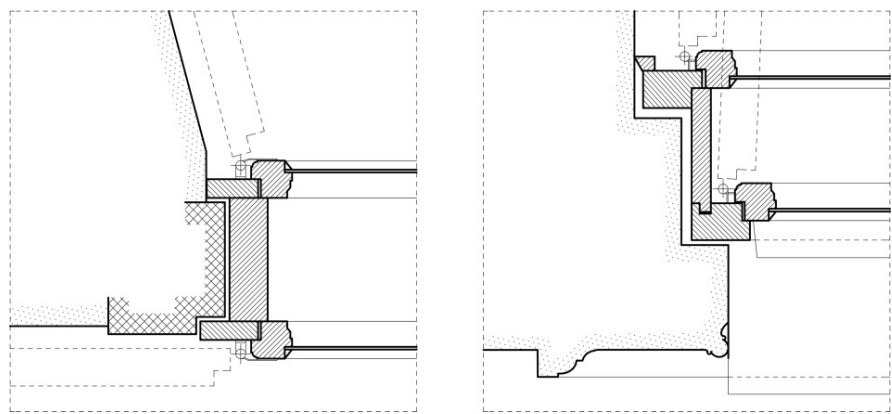

Fig. 1 Schematic representation of the jamb detail of two typical $19^{\text {th }}$ century box type windows

These differences warrant a detailed investigation of the fenestration heat transfer models' applicability for calculating box type windows. This paper reviews the models describing the convective heat transfer in enclosed cavities (a key part of fenestration heat transfer models) and analyses their accuracy for the specific case.

\section{The "convection in a rectangular cavity" problem}

The starting point for studying the natural convection heat transfer in windows is the simplified case of a gas filled rectangular cavity with two differentially heated (or cooled) surfaces. By creating a temperature difference across these surfaces of the enclosure, a natural convection is initiated by the temperature gradient. This convection is a function of many parameters:

- The geometry of the cavity (see Fig. 2) described by the following parameters:

- $\mathrm{L}[\mathrm{m}]$ - the thickness of the cavity in the $\mathrm{x}$ direction (the horizontal distance of the opposing faces where the temperature difference is applied)

- $\mathrm{W}[\mathrm{m}]$ - the width of the cavity in the y direction (the horizontal dimension of the cavity perpendicular to the main temperature gradient)

- $\mathrm{H}[\mathrm{m}]$ - the height of the cavity in the $\mathrm{z}$ direction

- $\varphi\left[{ }^{\circ}\right]-$ the angle of inclination of the cavity (if it is not vertical)

- The thermal boundary conditions: the surface temperature of the two differentially heated surfaces (if they are isothermal) and a description of the other surfaces, which can be either adiabatic or have a constant temperature gradient between the two heated surfaces (linear temperature profile). These are simplifying assumptions necessary to devise measurement methods and enable simple analytical solutions, and they will later be abandoned. Isothermal heated (or cooled) cavity surfaces are specified by their surface temperatures:

- $\mathrm{T}_{\mathrm{H}}[\mathrm{K}]$ - the temperature of the hot side of the cavity

- $\mathrm{T}_{\mathrm{C}}[\mathrm{K}]$ - the temperature of the cold side of the cavity

- The physical properties of the gas filling the cavity:

- $\mu[\mathrm{kg} / \mathrm{ms}]-$ the dynamical viscosity

- $\rho\left[\mathrm{kg} / \mathrm{m}^{3}\right]-$ the density
- $\lambda[\mathrm{W} / \mathrm{mK}]-$ the thermal conductivity

- $\mathrm{c}_{\mathrm{p}}[\mathrm{J} / \mathrm{kgK}]$ - the specific heat (at constant pressure)

- $\beta[1 / \mathrm{K}]-$ the thermal expansion coefficient

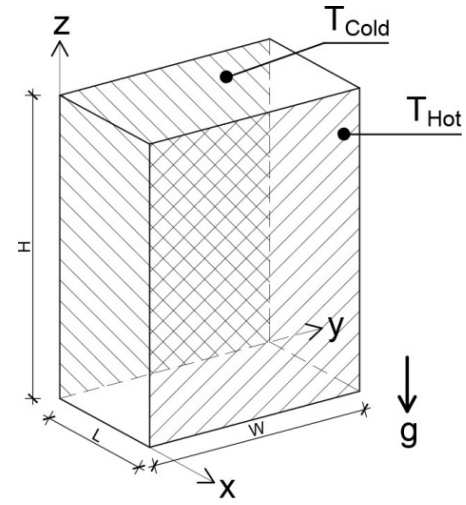

Fig. 2 A schematic representation of the 'natural convection in a rectangular differentially heated cavity' problem

Besides the study of the actual temperature, velocity, and pressure fields in the fluid, the determination of the overall convective heat transfer between the two differentially heated surfaces and the derivation of simple easy-to-use methods for its calculation are the main goals of most of the research done on the problem. This requires the reduction of the number of influencing parameters, which is usually achieved with the help of dimensional analysis. The dimensionless groups most commonly used to describe the problem are the dimensionless aspect ratio, the Prandtl, Grashof, Rayleigh and Nusselt numbers. As a further simplification, the flow is usually taken to be two-dimensional, which is accurate enough if the width of the cavity is sufficiently larger than its thickness (which is true for most fenestration glazing cavities).

The dimensionless aspect ratio is simply defined as the ratio between the total cavity height and the cavity thickness:

$$
A=\frac{H}{L}
$$

where: A $[-]-$ the dimensionless aspect ratio

$\mathrm{H} \quad[\mathrm{m}]-$ the total height of the cavity

$\mathrm{L} \quad[\mathrm{m}]-$ the thickness of the cavity in the direction of the main temperature difference

The Prandtl number is a material property of the fluid (and the fluid's state - e.g. temperature) and it is a measure of the ratio between the viscous (or momentum) and thermal diffusion rates:

$$
\operatorname{Pr}=\frac{\mu c_{p}}{\lambda}=\frac{v}{\alpha}
$$

where: $\operatorname{Pr}$

[-] - the Prandtl number

$\mu \quad[\mathrm{kg} / \mathrm{ms}]-$ the dynamic viscosity

$\mathrm{c}_{\mathrm{p}} \quad[\mathrm{J} / \mathrm{kgK}]-$ the specific heat capacity 


$\begin{array}{ll}\lambda & {[\mathrm{W} / \mathrm{mK}]-\text { the thermal conductivity }} \\ v & {\left[\mathrm{~m}^{2 / \mathrm{s}}\right]-\text { the kinematic viscosity }} \\ \alpha & {\left[\mathrm{m}^{2} / \mathrm{s}\right]-\text { the thermal diffusivity }}\end{array}$

If $\operatorname{Pr}<<1$ the thermal diffusion will tend to dominate and the thermal boundary layer will be much thinner than the momentum boundary layer, and if $\operatorname{Pr}>>1$ the opposite will be true. For most gases, the Prandtl number is approximately constant for a wide range of temperatures and pressures, and for our purposes (building physics) it can be taken as $\operatorname{Pr}=0.71$ [-]. This indicates that both thermal diffusion and convection effects will be around the same order of magnitude.

The Grashof number is used to describe natural convection, and can be thought of as the ratio of buoyant to viscous forces in a unit volume of the fluid:

$$
G r=\frac{g \Delta \rho V}{\rho v^{2}}=\frac{g \beta\left(T_{1}-T_{2}\right) l^{3}}{v^{2}}
$$

\begin{tabular}{|c|c|c|}
\hline where: & $\mathrm{Gr}$ & {$[-]$ - the Grashof number } \\
\hline & g & {$\left[\mathrm{m}^{2} / \mathrm{s}\right]-$ the acceleration of gravity } \\
\hline & $\rho$ & {$\left[\mathrm{kg} / \mathrm{m}^{3}\right]-$ the density } \\
\hline & $\mathrm{V}$ & {$\left[\mathrm{m}^{3}\right]-$ the volume } \\
\hline & $v$ & {$\left[\mathrm{~m}^{2 /} \mathrm{s}\right]-$ the kinematic viscosity } \\
\hline & $\beta$ & {$[1 / \mathrm{K}]-$ the thermal expansion coefficient } \\
\hline & $\mathrm{T}$ & {$[\mathrm{K}]-$ temperature } \\
\hline & 1 & [m] - the characteristic length \\
\hline
\end{tabular}

For natural convection in a rectangular cavity, the temperatures are usually taken as the surface temperatures of the differentially heated surfaces and the characteristic length 1 as the thickness of the cavity: L. If $\mathrm{Gr}>>1$ buoyancy dominates over viscosity.

The Rayleigh number is the product of the Prandtl and Grashof numbers, and is widely used in the description of natural convection problems:

$$
R a=G r * \operatorname{Pr}=\frac{\rho^{2} l^{3} g c_{p} \Delta T}{\mu \lambda T_{m}}
$$

where: $\mathrm{Ra}$

$\mathrm{Gr}$

$\operatorname{Pr}$

$\rho$

g

$\mathrm{c}_{\mathrm{p}}$

$\Delta \mathrm{T}$

$\mu$

$\lambda$

$\mathrm{T}_{\mathrm{m}}$
[-] - the Rayleigh number

$[-]$ - the Grashof number

$[-]$ - the Prandtl number

$\left[\mathrm{kg} / \mathrm{m}^{3}\right]$ - the density

$\left[\mathrm{m} / \mathrm{s}^{2}\right]$ - the acceleration of gravity

$[\mathrm{J} / \mathrm{kgK}]$ - the specific heat capacity

$[\mathrm{K}]$ - the temperature difference

$[\mathrm{kg} / \mathrm{ms}]$ - the dynamic viscosity

$[\mathrm{W} / \mathrm{mK}]$ - the thermal conductivity

$[\mathrm{K}]$ - the average temperature of the fluid
The heat transfer is dominated by thermal diffusion below and by convection above a certain critical Rayleigh number. The Rayleigh number is normally used to derive equations that are true for different types of fluids as it is a function of both the balance between buoyant and viscous forces and the fluid material properties.

The Nusselt number is defined as the ratio of the convective and conductive heat transfer coefficients across a fluid in natural convection:

$$
N u=\frac{h_{\text {conv }}}{h_{\text {cond }}}=\frac{h_{\text {conv }}}{\frac{1}{R_{\text {cond }}}}=\frac{h_{\text {conv }}}{\frac{\lambda}{d}}
$$

where: $\mathrm{Nu} \quad[-]-$ the Nusselt number

$\mathrm{h}_{\text {conv }} \quad\left[\mathrm{W} / \mathrm{m}^{2} \mathrm{~K}\right]-$ the convective heat transfer coefficient

$\mathrm{h}_{\text {cond }} \quad\left[\mathrm{W} / \mathrm{m}^{2} \mathrm{~K}\right]-$ the conductive heat transfer coefficient

$\mathrm{R}_{\text {cond }}\left[\mathrm{m}^{2} \mathrm{~K} / \mathrm{W}\right]-$ the conductive heat transfer resistance

$\lambda \quad[\mathrm{W} / \mathrm{mK}]-$ the thermal conductivity

$\mathrm{d} \quad[\mathrm{m}]-$ the characteristic thickness (the thickness of the cavity)

The conductive heat transfer coefficient is the heat transfer coefficient of an imaginary stagnant body of fluid where heat transport happens only by thermal conduction (thermal diffusion). If $\mathrm{Nu} \approx 1$, the convective heat transfer is negligible, and for heat transport, the fluid is stagnant. In the cavity convection problem, a $\approx 1$ Nusselt number means a near zero velocity perpendicular to the heated boundaries over much of the cavity. If $\mathrm{Nu}>1$, the convective heat transfer will become important and in the case of $\mathrm{Nu} \gg>1$ starting to dominate over thermal diffusion.

Since the cavity thickness is usually known and the thermal conductivity of the fill gas is easy to determine (in the conditions usually encountered in building physics it is a function of the gas temperature only), the Nusselt number is the most convenient way to describe the total convective heat flow across the cavity. The determination of the Nusselt number from the other properties is thus the main task in most thermal calculations of cavity convection, and a considerable body of work is devoted to it. This is done either by measurement, CFD simulations or with simple empirical equations previously derived from the last two. The equations are called Nusselt correlations as they are derived from analysing the relationship between the Nusselt number and the other dimensionless groups mentioned earlier. All fenestration heat transfer calculation methods have a set of Nusselt correlations in their algorithms that were selected from the literature or developed for the explicit purpose of modelling the thin cavities of insulating glass units. 


\section{Literature review}

Natural convection in differentially heated rectangular enclosed cavities is a problem of interest for many scientific and engineering fields. As a result, we can find a truly large number of publications devoted to the subject. Those most important for the calculation of glazing systems will be briefly summarized here.

Batchelor (1954) was one of the first researchers to investigate the temperature field in a rectangular enclosure with isothermal differentially heated surfaces. His work focused on laminar flows with relatively low Grashof or Rayleigh numbers. He was the first to identify the so-called 'conduction' and 'boundary layer' flow regimes based on analytical principles. A flow is in the conduction regime when it is under a certain Gr or Ra number and the heat transfer is predominantly via heat conduction (thermal diffusion) in the fluid (see Fig. 3). This regime is characterized by a constant temperature gradient across the cavity between the heated surfaces, a temperature field that satisfies the Laplace equation much like the temperature field one would encounter in a homogeneous solid material after the steady-state is reached. But if the Gr and Ra numbers are increased (e.g. by increasing the temperature difference), the flow will enter the boundary layer regime where the heat transfer is instead due mainly to convection (see Fig. 4). Distinct boundary layers form with high-temperature gradients at the two heated surfaces while the core of the fluid between these layers will demonstrate a near zero horizontal temperature gradient. Batchelor predicted that the core will show no vertical temperature gradients either (completely isothermal core). This later turned out to be incorrect.

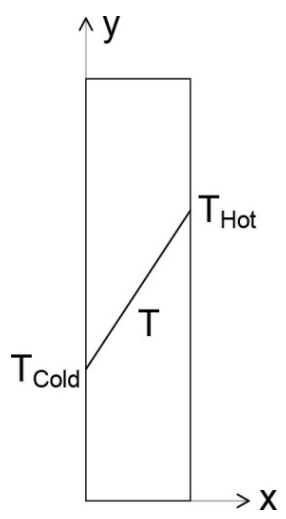

Fig. 3 Schematic representation of the conduction regime

Eckert and Carlson (1961) conducted an interferometry experiment to investigate the temperature field in differentially heated cavities of different sizes and aspect ratios at different Grashof numbers. They confirmed the existence of the distinct conduction (Fig. 5) and boundary layer regimes (Fig. 7) reported by Batchelor at low Gr numbers above a certain aspect ratio and high Gr numbers under a certain aspect ratio respectively. Unlike Batchelor, however, they also noted the existence of a third flow regime between the last two: the so-called transition regime (Fig. 6). In these transitional flows the temperature field no longer satisfies the Laplace equation: a stronger temperature gradient starts to form near the boundaries but these temperature boundary layers still interact in the core and the fully formed boundary layer regime is not yet reached. Sometimes, this kind of flow is also characterized by the emergence of a series of secondary convection cells. Another of their findings was the existence of a strong vertical temperature stratification in the fluid core in the boundary layer regime, which goes contrary to Batchelor's isothermal core hypothesis.

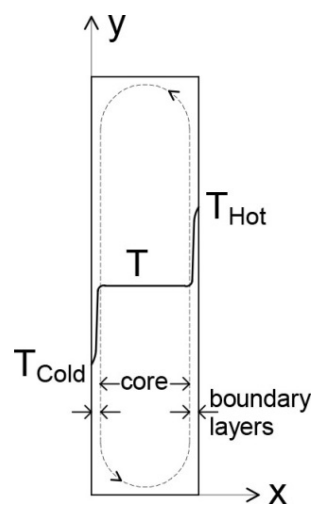

Fig. 4 Schematic representation of the boundary layer

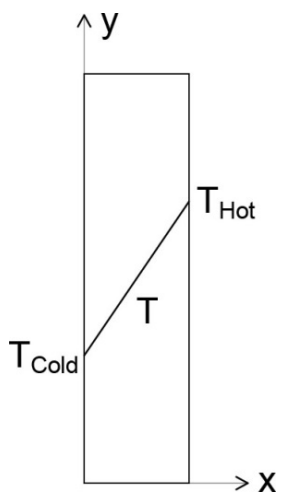

Fig. 5 Schematic representation of the conduction regime

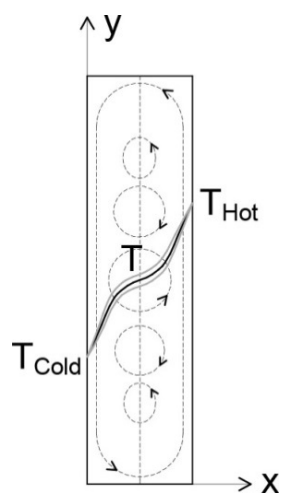

Fig. 6 Schematic representation of the transition regime with secondary convection cells 


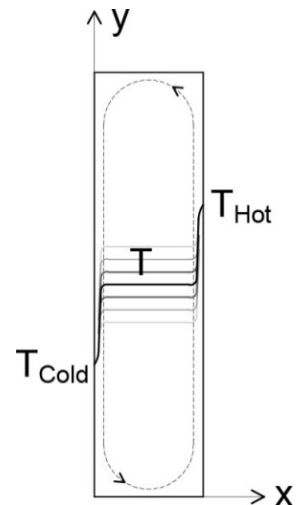

Fig. 7 Schematic representation of the conduction regime, with a vertical temperature gradient in the fluid core

Eckert and Carlson did not perform enough experiments to pin down the exact limits of transition between the different flow regimes very reliably, but they did derive two correlations for the Nusselt number in the conduction and the boundary layer regimes respectively. These use the aspect ratio and the Grashof number.

The correlation for the conduction regime:

$$
N u_{\text {cond }}=1+0.00166 \cdot\left(G r_{L}\right)^{0.9} \cdot A
$$

where:

$\mathrm{Nu}_{\text {cond }}[-]-$ the Nusselt number for the conduction regime

$\mathrm{Gr}_{\mathrm{L}} \quad[-]-$ the Grashof number based on the cavity thickness

A $\quad[-]-$ the dimensionless aspect ratio

The correlation for the boundary layer regime:

$$
N u_{B L}=0.119 \cdot\left(G r_{L}\right)^{0.3} \cdot A^{-0.1}
$$

where:

$$
\begin{array}{ll}
\mathrm{Nu}_{\text {cond }} & {[-]-\text { the Nusselt number for the conduction }} \\
& \text { regime } \\
\mathrm{Gr}_{\mathrm{L}} & {[-]-\text { the Grashof number based on the cavity }} \\
& \text { thickness } \\
\mathrm{L} & {[\mathrm{m}]-\text { the cavity thickness }} \\
\mathrm{H} & {[\mathrm{m}]-\text { the cavity height }}
\end{array}
$$

These correlations have limited applicability since they lack a description of the transition regime. Their correlations are based on data gathered for cavity aspect ratios of $\mathrm{A}=2.5-46.7$ [-] and Grashof numbers of $\mathrm{Gr}=8 \mathrm{e} 4-2 \mathrm{e} 5$ [-]. The limits of transition between the different flow regimes they proposed are shown in Fig. 13.

Elder (1965) conducted experiments on natural convection for cavities with aspect ratios of $A=1-60$ [-] and Rayleigh numbers of $\operatorname{Ra}<1 \mathrm{e} 8$ [-] with a fluid of $\operatorname{Pr}=103$ [-]. The heated cavity walls were kept isothermal. For $\mathrm{Re}<1 \mathrm{e} 3$ the temperature field closely satisfied the Laplace equation (conduction regime), although, even here, a single cell convection is still present but with nonzero horizontal velocities only around the top and bottom edges of the cavity (up to a distance of around L) (see Fig. 8). Between $\mathrm{Re}=1 \mathrm{e} 3[-]$ and $\mathrm{Re}=1 \mathrm{e} 5[-]$, the temperature gradients next to the heated wall begin to grow, and a vertical temperature stratification starts to form in the core. At around $\mathrm{Ra}=1 \mathrm{e} 5$ [-] a 'cat's eye pattern' of secondary convection cells is starting to form that grow larger in amplitude and begin to interact at around $\mathrm{Ra}=1 \mathrm{e} 6$ [-] (Fig. 9). The boundary layers have a thickness that is $\sim \operatorname{Ra}^{\wedge} 1 / 4$. The higher the Rayleigh number gets, the thinner the boundary layers become, which finally results in the boundary layer regime described earlier (Fig 10).

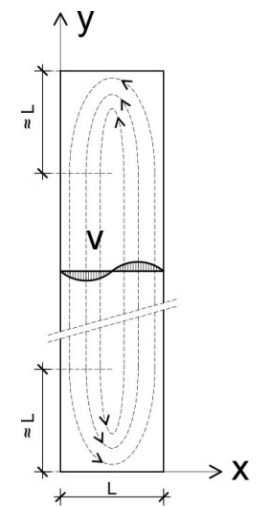

Fig. 8 Schematic representation of the flow in the conduction regime

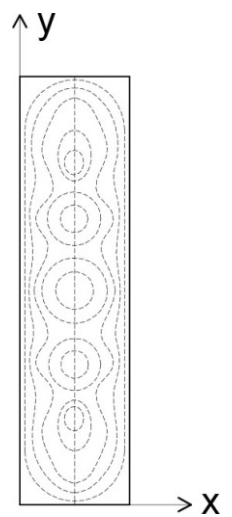

Fig. 9 Schematic representation of the flow in the transition regime

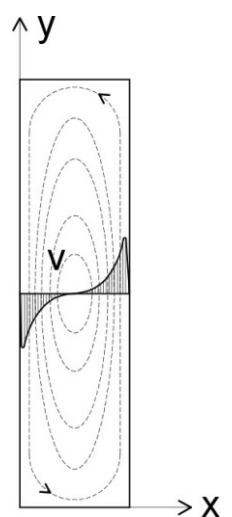

Fig. 10 Schematic representation of the flow in the boundary layer regime 
In his 1967 book, Jakob (1967) proposed another correlation for the Nusselt number based on earlier experimental datasets. The correlation is derived for cavities with $\mathrm{A}=3.12-42.2[-]$ and $\mathrm{Gr}=2 \mathrm{e} 4-2 \mathrm{e} 5[-]$. The correlation takes the following form:

$$
N u=0.18 \cdot\left(G r_{L}\right)^{0.25} \cdot A^{-0.111}
$$

The Nusselt number is thus found to be directly proportional to the temperature gradient and inversely proportional to the aspect ratio, albeit only weakly. This form of correlation $-\mathrm{Nu}=$ $\mathrm{C} * \mathrm{Gr}^{\wedge} \mathrm{a} * \mathrm{~A}^{\wedge} \mathrm{b}-$ is found in the works of many other authors as well: Newel and Schmidt (1970), Yin et al. (1978), Eckert and Carlson (1961) and Yang (2003).

Newell and Schmidt (1970) used a Finite Difference Method based CFD code to study the laminar convective heat transfer in rectangular cavities with $\mathrm{A}=2.5-20[-]$ and $\mathrm{Gr}=4 \mathrm{e} 3-1.4 \mathrm{e} 5[-]$. Their Nu number results gave the following correlation with the $\mathrm{A}$ and $\mathrm{Gr}$ numbers:

$$
N u=0.115 \cdot G r^{0.315} \cdot A^{-0.265}
$$

Hollands et al. (1976), in their 1976 article, studied the free convection in inclined rectangular cavities with high aspect ratios of $\mathrm{A}>20$ [-], Rayleigh numbers of $\mathrm{Ra}<1 \mathrm{e} 5[-]$ and inclinations of $0^{\circ} \leq \varphi<70^{\circ}$ with upward heat transport (heated from below, cooled from above). They proposed a new correlation for the Nusselt number that is today incorporated into the widely used international and harmonized European standard ISO 15099 (2003):

$$
\begin{aligned}
N u & =1+1.44 \cdot\left[1-\frac{1708}{R a \cdot \cos (\varphi)}\right]^{\bullet} \cdot\left[1-\frac{\left(1708 \sin ^{2}(1.8 \cdot \varphi)\right)}{R a \cdot \cos (\varphi)}\right] \\
& +\left[\left[\frac{R a \cdot \cos (\varphi)}{5830}\right]^{1 / 3}-1\right]^{\bullet}
\end{aligned}
$$

where: $[x]^{\bullet}=(x+|x|) / 2$

$$
\begin{array}{ll}
\mathrm{Nu} & {[-]-\text { the Nusselt number }} \\
\mathrm{Ra} & {[-]-\text { the Rayleigh number }} \\
\varphi & {\left[^{\circ}\right]-\text { the inclination of the cavity (from }} \\
& \text { horizontal) }
\end{array}
$$

Yin et al. (1978) conducted natural convection experiments for air-filled cavities with aspect ratios of $\mathrm{A}=4.9-78.7[-]$ over a wide range of Grashof numbers: Gr=1.5e3-7e6 [-]. They measured temperature profiles and overall heat transfer rates and derived a correlation for the Nusselt number dependent on both the Grashof number and the aspect ratio:

$$
N u=0.21 \cdot G r^{269} \cdot A^{-0.131}
$$

Yin et al. (1978) also proposed values for the limits of transition (Gr or Ra numbers) between the conduction, transition and boundary layer regimes, as well as between laminar and turbulent flows depending on the cavity aspect ratio (see Fig. 13).
Raithby and Wong (1981) performed numerical simulations to come up with a new correlation for the Nusselt number for cavities with $\mathrm{A}=2-80[-]$ and $\mathrm{Ra}=1 \mathrm{e} 3-2 \mathrm{e} 5[-]$ :

$$
N u=\left(1+\left(\frac{0.344 \cdot R a^{0.25}}{1+\frac{112}{R a^{10.87}}}\right)^{2}\right)^{0.5}
$$

Where Ra' is given by the following expressions depending whether the side walls of the cavity were modelled with a linear temperature profile or as adiabatic:

$$
\begin{aligned}
& R a^{\prime}=\left(1-\frac{1.02}{A^{0.44}}\right) \cdot \frac{R a}{A} \quad \text { for a linear temperature profile } \\
& R a^{\prime}=\left(0.89-\frac{0.73}{A}\right) \cdot \frac{R a}{A} \quad \text { for adiabatic side walls }
\end{aligned}
$$

ElSherbiny et al. conducted one of the most comprehensive and most cited measurement campaigns in the literature about natural convection in rectangular cavities. In a first publication (ElSherbiny et al., 1982a) they investigated the effect the treatment of the side wall boundary conditions have on measurement results. Most convective heat transfer measurements are done by creating a linear temperature profile at the side walls of the cavity. While this is a good fit for flows in the conduction regime where the temperature gradient in the fluid is itself linear, which results in basically no sideways heat flux, it complicates matters when a boundary layer regime flow is investigated. Here, especially at the top and bottom zones of the cavity, the core of the fluid is close to either the cold or the hot boundary temperature while the solid wall of the cavity tries to enforce a linear temperature profile, which will lead to nonzero sideways heat flux.

In their second paper (ElSherbiny et al., 1982b), they present an extensive set of measurement data of Nusselt numbers for air-filled cavities with aspect ratios between 5 and 110 and Rayleigh numbers of $\mathrm{Ra}=1 \mathrm{e} 2-2 \mathrm{e} 7$ [-]. Besides publishing the raw data, they propose a whole set of correlations for the $\mathrm{Nu}$ number. These are a series of six equations valid only for distinct aspect ratios but with a better fit and two more complex correlation functions, which incorporate the whole range of the measurements called design correlations for vertical and for inclined cavities of arbitrary aspect ratios and Rayleigh numbers. The measurements were done with isotherm heated surfaces and linear temperature profiles at the side walls.

The six equations for the Nusselt number in cavities for distinct aspect ratios:

$$
\begin{aligned}
& N u=\left\{\left[1+\left(\frac{0.193 R a^{0.25}}{1+(1800 / R a)^{1.289}}\right)^{3}\right]^{1 / 3}, 0.0605 * R a^{1 / 3}\right\}_{\text {max }} \\
& \text { for } A=5[-], R a<1 e 8[-]
\end{aligned}
$$




$$
\begin{gathered}
N u=\left\{\left[1+\left(0.125 R a^{0.28}\right)^{9}\right]^{1 / 9}, 0.061 * R a^{1 / 3}\right\}_{\max } \\
\text { for } A=10[-], R a<9.7 e 6[-] \\
N u=\left[1+\left(0.064 R a^{1 / 3}\right)^{6.5}\right]^{1 / 6.5} \text { for } A=20[-], R a<2 e 6[-] \\
N u=\left[1+\left(0.0303 R a^{0.402}\right)^{11}\right]^{1 / 11} \text { for } A=40[-], R a<2 e 5[-] \\
N u=\left[1+\left(0.0227 R a^{0.438}\right)^{18}\right]^{1 / 18} \text { for } A=80[-], R a<3 e 4[-] \\
N u=\left[1+\left(0.0607 R a^{1 / 3}\right)^{18}\right]^{1 / 18} \text { for } A=100[-], R a<1.2 e 4[-]
\end{gathered}
$$

These equations are regarded by many authors as the most accurate to date. The general purpose multi-aspect ratio correlations they propose finds the actual Nusselt number as the maximum of three functions:

$$
N u=\operatorname{Max}\left[\begin{array}{l}
N u_{1}=0.0605 R a^{1 / 3} \\
\left.N\left(\frac{0.104 R a^{0.293}}{1+\left(\frac{6310}{R a}\right)^{1.36}}\right)^{3}\right]^{1 / 3} \\
N u_{3}=0.242\left(\frac{R a}{A}\right)^{0.272}
\end{array}\right]
$$

$\mathrm{Nu}_{1}$ usually describes the flow in case of large Ra numbers (boundary layer regime), $\mathrm{Nu}_{2}$ in the conduction regime and $\mathrm{Nu}_{3}$ in the transition regime.

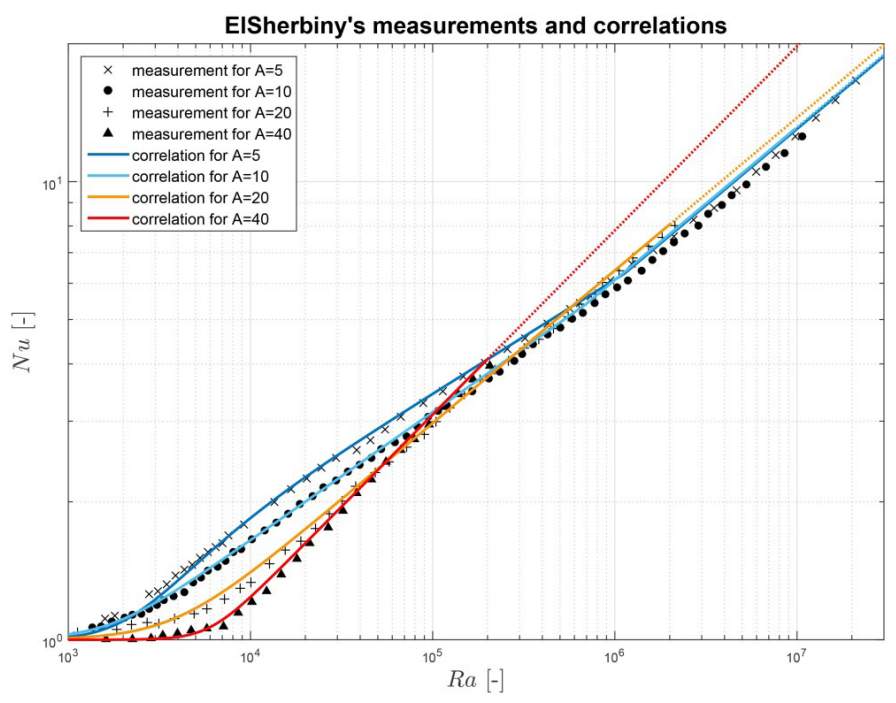

Fig. 11 The measurement data of ElSherbiny et al. (1982b) (for $A=5-40)$ and their correlations for distinct aspect ratios (the dashed end of the lines represent the correlations extrapolated outside their reported range of validity)
For inclined cavities - with inclinations between $60^{\circ}$ and $90^{\circ}$ - they propose the following method: there is a correlation for an inclination of $60^{\circ}$ while values for other inclinations are found with linear interpolation between the $60^{\circ}$ and $90^{\circ}$ values. The correlation for $60^{\circ}$ is:

$$
\begin{gathered}
N u_{1}=\left[1+\left[\frac{0.0936 \cdot R a^{0.314}}{1+G}\right]^{7}\right]^{1 / 7} \\
G=\frac{0.5}{\left[1+\left[\frac{R a}{3160}\right]^{20.6}\right]^{0.1}} \\
N u_{2}=\left[0.104+\frac{0.175}{A}\right] \cdot R a^{0.283} \\
N u=\operatorname{Max}\left(N u_{1}, N u_{2}\right)
\end{gathered}
$$

Lee and Korpela (1983) studied multicellular convection in the transition regime with numerical simulations to find the critical Gr numbers where this kind of flow pattern is encountered. They investigated aspect ratios of 10-40 [-] and a wide range of Grashof numbers, and developed a simple equation for the aspect ratio dependent limit:

$$
G r_{c}=\frac{1+\frac{5}{A}}{1.25 \cdot 10^{-4}}
$$

The limit is visualized in Fig. 13. Under an aspect ratio of $\mathrm{A}=12$ [-] secondary flow was not detected. Their results compared well with measurements done with smoke aided flow visualization and interferometry.

Shewen et al. (1989) have developed a new method for the simultaneous heating or cooling of, and heat flux measurement on cavity walls in experimental apparatus aimed at the study of natural convection in rectangular cavities based on the Peltier effect. Relying on this work, in another article Shewen et al. (1996), they present their measurements and a correlation for the Nusselt number for cavities with aspect ratios of 40 or larger and Rayleigh numbers less than 1e6. The aspect ratio and Rayleigh number range is clearly aimed at insulating glass units.

$$
N u=\left[1+\left(\frac{0.0665 \cdot R a^{1 / 3}}{1+\left(\frac{9000}{R a}\right)^{1 / 4}}\right)^{2}\right]^{1 / 2}
$$

Wright and Sullivan (1989) present an exhaustive literature review of works concerning the modelling of the natural ventilation in rectangular cavities in their effort to find a suitable model for predicting the lowest internal surface temperature at the bottom edge of insulating glass units. IG units have typical cavity 
aspect ratios of around 70 or higher, but relatively low typical $\mathrm{Ra}$ numbers. A well sized IG unit is usually in the conduction regime where the flow is very weak and strictly vertical throughout most of the glazing. However, even the weak convection cell of a conduction regime flow must close and loop around at the bottom and top edges. Here, the normally linear temperature profile gets distorted: the bottom edge gets cooler and the top edge warmer at the interior side due to convective cooling or heating. This is the reason why the minimum surface temperature prediction of most thermal bridge simulation programs that only solve the Fourier equation, are unreliable in these regions.

In another article, Wright (1996) analyses the Ra-Nu data and correlations of ElSherbiny et al. (1982a; 1982b) and Shewen et al. (1996) for the A and Ra number region most interesting for the thermal calculation of insulating glass units: $A>40[-]$ and $\mathrm{Ra}<1 \mathrm{e} 6$ [-]. Every correlation starts with the conduction regime at the smallest $\mathrm{Ra}$ numbers, where $\mathrm{Nu}=1[-]$ and ends with the very large Ra numbers of the fully developed turbulent boundary layer flows where the slope of the Ra-Nu function is found to be around $1 / 3$ on a logarithmic plot by all authors. The transition from the conduction to the transition and from the transition to the fully formed turbulent boundary flow regimes is shown to be a function of A. Taller cavities leave the conduction regime earlier and can become turbulent at smaller $\mathrm{Ra}$ values than cavities with a smaller aspect ratio. The transitional $\mathrm{Nu}$ numbers at low A values are highly dependent on the A value itself and are represented by a bend in the $\mathrm{Ra}-\mathrm{Nu}$ functions between the conduction and boundary layer regimes. At high values of $\mathrm{A}$, its effect becomes smaller and impossible to quantify reliably due to the unpredictability of the secondary flows in the transition regimes. Or at least this was the case in ElSherbiny's (1982a) dataset Wright used. They conclude that an A value independent correlation is required.

Wright selects the measurements of Sheven for $A=60,80$ and 110, as well as ElSherbiny's data to derive his own correlations that are tailored to the zone of insulating glazing units $-\mathrm{A}>40$ [-] and $\mathrm{Ra}<1 \mathrm{e} 5$ [-]. The correlation is derived to minimize the errors in the zone where the unresolved A value dependence creates disturbances in the data. Ra values between $1 \mathrm{e} 5$ and $1 \mathrm{e} 6$ were added to the dataset to account for krypton gas fills and the larger pane spacing of storm windows. The new set of correlations is:

$$
N u=\operatorname{Max}\left[\begin{array}{l}
N u_{1}=\left(\begin{array}{l}
0.0673838 \cdot R a^{1 / 3} \text { for } \mathrm{Ra}>5^{*} 10^{4} \\
0.028154 \cdot R a^{0.41399} \text { for } 10^{4}<R a \leq 5^{*} 10^{4} \\
1+1.75967 \cdot 10^{-10} \cdot R a^{2.2984755} \text { for } \mathrm{Ra} \leq 10^{4}
\end{array}\right) \\
N u_{2}=0.242\left(\frac{R a}{A}\right)^{0.272}
\end{array}\right]
$$

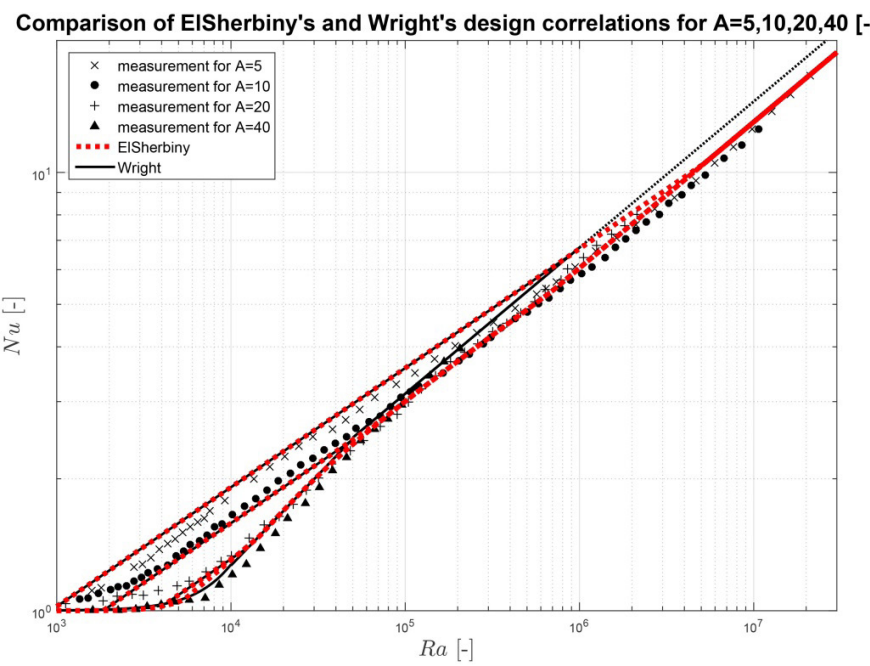

Fig. 12 The measurement data of ElSherbiny et al. (1982b) (for A=5-40) and Wright's (1996) general correlations (the dashed end of the lines represent the correlations extrapolated outside their reported range of validity)

Although the data used for the derivation stopped at $\mathrm{Ra}=1 \mathrm{e} 6$ [-] Wright claims that there is no theoretical limit to the validity of the correlation in the even larger Ra numbers of the boundary layer regime. The 1/3 slope of the $\mathrm{Ra}-\mathrm{Nu}$ function in this region and the fact that $\mathrm{Ra}$ is proportional to the third power of the cavity thickness, means that the convective heat transfer coefficient in very large cavities will be independent of the cavity thickness. This shows that there is a theoretical maximum convective heat transfer resistance one can achieve with a single air gap.

In these equations, the term $\mathrm{Nu}_{2}$ does show a dependence on A, but it is only ever effective for $\mathrm{A}<25$ - outside the official validity range of the correlations.

The correlations presented by Wright are currently an integral part of the harmonized European and international standard EN ISO 15099 (2003) for the calculation of centre of glazing heat transfer indices of IG units and the widely used glazing thermal calculation program LBN WINDOW (Lawrence Berkeley National Laboratory: Window 7.3). However, the limitations in A and Ra values originally reported by Wright are not mentioned in either one. For cavities with smaller A values, where the A value dependence of the Nusselt number is more important, Wright suggests using the original six correlations of ElSherbiny (1982b) instead.

In the article, Wright (1998) introduce a model for the calculation of minimum surface temperatures of windows that, instead of a purely conduction calculation, relies on a oneway coupling between a CFD simulation for the velocity field in a glazing cavity and the thermal conduction calculation in the solid parts (frame, glazing, etc.). A precalculated velocity field in the glazing cavity is used to define the convective heat transfer in the thermal simulation of the glazing-spacer-frame assembly. The program can handle both simple conduction regime and transition regime flows, but it was not intended for the boundary layer regime. 
Zhao et al. (1998) set out to improve the correlation of Wright, and to resolve the A value dependence of the Nussel numbers for cavities with an aspect ratio of 5-110 [-] and a Rayleigh number of up to 2e4 [-]. In their survey of the literature and the published data, they have found that $\mathrm{Nu}$ is always a function of $\mathrm{A}$ if $\mathrm{A}<40$ [-] and even between $\mathrm{A}=40-80$ [-] if $\mathrm{Ra}>5950$ [-], which is shown in the data of Lee and Korpela (1983), ElSherbiny et al. (1982b) and Yin et al. (1978) alike. Theoretically for the same Ra number, the Nu number should decrease with larger aspect ratios as a large part of the convective heat transfer happens at the top and bottom edges of the cavity where the flow loops around, the relative effect of which is decreased when the total height of the cavity is increased. ElSherbiny's data is found to show unphysical tendencies in this regard. Also, in ElSherbiny's measurement for A=40-110 [-], the transition point between the conduction and transition regimes is shown to deviate significantly from what is expected from the rest of the literature. Since the correlations of Wright (1996) are partly based on this dataset, they warn that they could require some revision.

Instead of measurement data, Zhao et al. used CFD simulation results to derive their new correlation since unlike measurements, CFD simulations can produce reproducible A value dependent Nusselt values in every flow regime. Their new correlation is:

$$
N u_{1}=\left[1+\left(\frac{0.788335 \cdot\left(\left(1.42227-\frac{1.41845}{A}\right) \frac{R a}{A}\right)^{0.881073}}{139.677+\left(\left(1.42227-\frac{1.41845}{A}\right) \frac{R a}{A}\right)^{0.724505}}\right)^{2}\right]^{0.5}
$$

for $5 \leq A \leq 30$

$$
N u_{2}=\left(1+0.00044265 \cdot\left(\frac{R a}{A}\right)^{1.36869}\right)^{0.326071} \text { for } 30<A \leq 110
$$

The new equation compares well with the data of ElSherbiny for $\mathrm{A}=5-20$ [-], but deviates for $\mathrm{A}=40-110$ [-] for the reason discussed earlier.

Zhao, Goss, Curcija and Power (1997) also studied the limits for multicellular patterns in the natural convection in rectangular cavities. Unlike Lee and Korpela (1983), they reported both lower and upper limits in Ra number for cavities with aspect ratios between 10.7 and 80 [-]. Their calculations showed an absolute lower limit of $\mathrm{A}=10.7$ [-] under which no multicellular flow occurred. In cavities with $A=10.7-30$ [-], the multicellular convection died before reaching the turbulence regime. Their Ra limits are shown in Fig. 13.

In his Ph.D. thesis, Power (1999) performed CFD simulations with the help of the Finite Element Method to study the transition between laminar and turbulent flow in the natural convection in rectangular differentially heated cavities. $\mathrm{He}$ used a transient solver to look for fluctuations in the solution that may indicate the onset of turbulence. He devised a powerlaw correlation between the $\mathrm{Ra}$ and A numbers for the transition limit that is shown in Fig. 13.

Power also proposed a new Nusselt number correlation in and around the laminar-turbulent transition regime; he investigated: $\mathrm{A}=5,10,20,30,40,50,60,80[-]$ and $\mathrm{Ra}=1 \mathrm{e} 4-5.25 \mathrm{e} 5$ [-]. His correlation is:

$$
N u=0.1098 \cdot\left(R a^{1 / 2} \cdot A^{-1 / 6}\right)^{0.6113}
$$

The range of validity for the correlation is:

$$
\begin{array}{ll}
3.5 \mathrm{e} 4<\mathrm{Ra}<5.25 \mathrm{e} 5 & \text { for } \mathrm{A}=20[-] \\
3 \mathrm{e} 4<\mathrm{Ra}<4.06 \mathrm{e} 5 & \text { for } \mathrm{A}=30[-] \\
1 \mathrm{e} 4<\mathrm{Ra}<1.7 \mathrm{e} 5 & \text { for } \mathrm{A}=40[-] \\
1 \mathrm{e} 4<\mathrm{Ra}<1 \mathrm{e} 5 & \text { for } \mathrm{A}=50[-] \\
2 \mathrm{e} 4<\mathrm{Ra}<4.4 \mathrm{e} 4 & \text { for } \mathrm{A}=60[-]
\end{array}
$$

Yang's dissertation (2003) studied several aspects of the natural convection in differentially heated rectangular cavities: the inclination angle dependence of the heat transfer, the modelling of turbulence in the flow, and the limits of transition between laminar and turbulent flow regimes. A new correlation for the Nusselt number is also presented. 2D CFD simulations of inclined cavities failed to produce any results that compared favourably with existing measurement data in the literature, indicating that this type of flow is strongly $3 \mathrm{D}$ in nature.

Yang used a k- $\omega$ turbulence model for his simulations and relied on the comparison of simulation with and without the turbulence model to find the laminar-turbulent transition points. According to his findings, the transition occurs at $\mathrm{Ra}=1 \mathrm{e} 9 * \mathrm{~A}^{\wedge}-3$ if $\mathrm{A}<33$ [-] and at $\mathrm{Ra} 360.418^{*} \mathrm{~A}^{\wedge}-0.7573$ if $33<\mathrm{A}<74$. This limit is in relatively good agreement with the results of both Power (1999) and Batchelor (1954) as seen in Fig. 13.

The new correlation for the Nusselt number is derived for aspect ratios of $\mathrm{A}=20-100$ [-] and Rayleigh numbers of $\mathrm{Ra}=2 \mathrm{e} 4-2 \mathrm{e} 5$ [-]:

$$
N u=0.0979573 \cdot R a^{0.310338} \cdot A^{-0.0860783}
$$

Xaman et al. (2005) performed CFD simulation with the Finite Volume Method with either a laminar or four different $\mathrm{k}-\varepsilon$ turbulence models for natural convection in cavities of aspect ratios of $\mathrm{A}=20,40$ and 50 [-] and Rayleigh numbers of $\mathrm{Ra}=1 \mathrm{e} 3-1 \mathrm{e} 6$ [-] for the laminar and $\mathrm{Ra}=1 \mathrm{e} 4-1 \mathrm{e} 8$ [-] for the turbulent simulations. From the four investigated turbulence models, they found the one of Ince and Launder (1989) to best agree with measurement data taken from the literature. They used this model to derive two sets of correlations of their own for the Nusselt number based on either laminar or turbulent calculations and for $\mathrm{A}=20,40$ and 80 [-].

The laminar correlations (for $1 \mathrm{e} 3 \leq \mathrm{Ra} \leq 1 \mathrm{e} 6$ ) are:

$$
N u=0.1731 \cdot R a^{0.2617} \text { for } A=20
$$




$$
\begin{gathered}
N u=0.1865 \cdot R a^{0.245} \text { for } A=40 \\
N u=0.1897 \cdot R a^{0.2398} \text { for } A=80
\end{gathered}
$$

The turbulent correlations (for $1 \mathrm{e} 4 \leq \mathrm{Ra} \leq 1 \mathrm{e} 8$ ) are:

$$
\begin{aligned}
& N u=0.0857 \cdot R a^{0.3033} \text { for } A=20 \\
& N u=0.0635 \cdot R a^{0.323} \text { for } A=40 \\
& N u=0.054 \cdot R a^{0.3335} \text { for } A=80
\end{aligned}
$$

By comparing their results with the correlations of Yin et al. (1978), ElSherbiny (1982b), Wright (1996), Zhao et al. (1998) and EN 673 (2011), they found that their laminar result agreed best with the data of Yin et al. and their turbulent results with most, except for EN 673. It must be noted, that their laminar calculation reached well into the fully turbulent regimes for $\mathrm{A}=40$ and 80 , and none of the data they used for comparison reached as far as theirs in the turbulent regime.

The European standard EN 673 (2011), for the calculation of the thermal transmittance of glazing systems, presents a single set of three correlations for the calculation of the $\mathrm{Nu}$ number dependent only on the Gr and Pr numbers (i.e. the Ra number) and the inclination of the cavity:

$$
\begin{gathered}
N u=0.035 \cdot(G r \cdot \operatorname{Pr})^{0.38} \text { for } \varphi=90^{\circ} \\
N u=0.1 \cdot(G r \cdot \operatorname{Pr})^{0.31} \text { for } \varphi=45^{\circ} \\
N u=0.16 \cdot(G r \cdot \operatorname{Pr})^{0.28} \text { for } \varphi=0^{\circ}
\end{gathered}
$$

For other inclinations, the Nu number is to be determined by linear interpolation. Their aspect ratio dependence is completely neglected.

The EN ISO 15099 (2003) standard is much more comprehensive than EN 673 (2011) as it incorporates both centre of glazing thermal and optical calculations and multi-dimensional calculations of heat transmission through glazing-spacer-frame assemblies as well as the effect of the addition of shading devices. The set of correlations found in the standard is a collection from the literature introduced above:

The correlation for vertical $\left(\varphi=90^{\circ}\right)$ cavities:

$$
N u=\operatorname{Max}\left[\begin{array}{l}
N u_{1}=\left(\begin{array}{l}
0.0673838 \cdot R a^{1 / 3} \text { for } \mathrm{Ra}>5^{*} 10^{4} \\
0.028154 \cdot R a^{0.41399} \text { for } 10^{4}<R a \leq 5^{*} 10^{4} \\
1+1.75967 \cdot 10^{-10} \cdot R a^{2.2984755} \text { for } \mathrm{Ra} \leq 10^{4}
\end{array}\right) \\
N u_{2}=0.242\left(\frac{R a}{A}\right)^{0.272}
\end{array}\right]
$$

For inclinations between $60^{\circ}$ and vertical $\left(60^{\circ}<\varphi<90^{\circ}\right)$, the Nusselt number is to be determined by linear interpolation between the $\mathrm{Nu}_{90}$ and $\mathrm{Nu}_{60}$ values. This is reported to be valid by the standard for cavities with $1 \mathrm{e} 2<\mathrm{Ra}<2 \mathrm{e} 7$ and $5<\mathrm{A}<100$.
The correlation for cavities inclined at $\varphi=60^{\circ}$ is:

$$
N u_{1}=\left[1+\left[\frac{0.0936 \cdot R a^{0.314}}{1+G}\right]^{7}\right]^{1 / 7}
$$

$$
G=\frac{0.5}{\left[1+\left[\frac{R a}{3160}\right]^{20.6}\right]^{0.1}}
$$

$$
\begin{gathered}
N u_{2}=\left[0.104+\frac{0.175}{A}\right] \cdot R a^{0.283} \\
N u=\operatorname{Max}\left(N u_{1}, N u_{2}\right)
\end{gathered}
$$

The correlation for cavities inclined at $0 \leq \varphi<60^{\circ}$ (valid for $\mathrm{Ra}<1 \mathrm{e} 5$ [-] and $\mathrm{A}>20[-])$ is:

$$
\begin{aligned}
N u & =1+1.44 \cdot\left[1-\frac{1708}{R a \cdot \cos (\varphi)}\right]^{\bullet} \cdot\left[1-\frac{\left(1708 \sin ^{2}(1.8 \cdot \varphi)\right)}{R a \cdot \cos (\varphi)}\right] \\
& +\left[\left[\frac{R a \cdot \cos (\varphi)}{5830}\right]^{1 / 3}-1\right]^{\bullet}
\end{aligned}
$$

where the operator: $[x]^{*}=(x+|x|) / 2$

The correlation for $\varphi=90^{\circ}$ is based on the work of Wright (1996), the ones for $\varphi=60^{\circ}$ and the method for interpolation for $60^{\circ}<\varphi<90^{\circ}$ on ElSherbiny et al. (1982b) and the correlation for $0 \leq \varphi<60^{\circ}$ on Hollands et al. (1976). The correlation for $\varphi=90^{\circ}$ is given without any limits on the A and Ra numbers, which is questionable as it was derived for a much more limited range of measurement values as we have seen earlier.

\section{Flow regimes of IG units and box type windows}

Figure 13 shows the Ra and A limits of the different flow regimes as described by the various authors in the literature review. Though the various sources don't agree with each other completely due to differences in methodology, possibly measurement and calculation accuracy issues and the different area they investigated, the approximate limits for the main flow types are clear.

By performing a simple Monte Carlo simulation on the expected range of the relevant geometrical and thermal parameters (cavity height, cavity thickness and temperature difference), we can determine the A and Ra number range we can expect to encounter in the cavities of IG units $(\mathrm{H}=0.4-3.5[\mathrm{~m}]$, $\mathrm{L}=0.04-0.025[\mathrm{~m}], \mathrm{dT}=1-30[\mathrm{~K}])$ and box type windows $(\mathrm{H}=1-$ $3.5[\mathrm{~m}], \mathrm{L}=0.1-0.2[\mathrm{~m}], \mathrm{dT}=1-30[\mathrm{~K}])$ respectively. The results are shown in grey and red dots on the chart. 


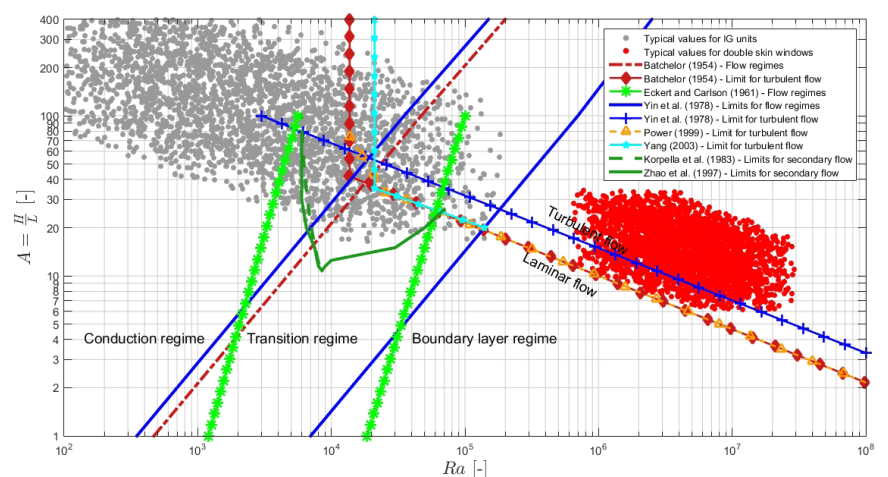

Fig. 13 The different flow regimes reported in the literature dependent on the $\mathrm{Ra}$ and A numbers and the typical A-Ra number pairs for IG units and box type windows

Insulating Glass units have typical aspect ratios of 30-40 [-] and more, and their thin cavities limit the Ra number to relatively low values $(<10 \mathrm{e} 5[-])$ for most cases (as the Ra number is proportional to the third power of cavity thickness). As a result, most IG units are in the laminar conduction regime; only for small aspect ratios and very large Ra numbers (relatively large cavity thickness and large temperature difference) do they reach into the transition regime. An example for such an extreme case would be a very small IG unit with an above standard cavity width. Both Batchelor (1954) and Yang (2003) reported a bottom Ra number limit for the onset of turbulence (Unlike Yin et al. (1978)). This limit is quite high, so turbulence is also rarely encountered; although the creation of secondary convection cells can occur at slightly smaller Rayleigh numbers.

The large cavities of box type windows occupy a different position on the chart. The aspect ratio ranges from 6 to around 33 [-] and the Rayleigh number from $6 \mathrm{e} 5$ to $3 \mathrm{e} 7[-]$. This puts these cavities clearly in the turbulent boundary layer flow regime (except for the smallest of temperature differences that are right at the edge of turbulence). They are well above the upper limit for secondary flows, but according to Batchelor (1954), and Eckert and Carlson (1961), a pronounced vertical temperature stratification is expected instead, which is a characteristic of boundary layer regime flows.

\section{Critical analysis of $\mathrm{Nu}$ correlations for the case of box type windows}

The correlations found in the literature to calculate the $\mathrm{Nu}$ number are summed up in Table 1 with the A, Pr, Gr or Ra number ranges they were based on. These ranges are often neglected but are important as equations should only be used which were derived and validated for the flow regime under investigation. The range of the most important studies is also visualized in Fig. 14.
As mentioned earlier, the correlation of Wright (1996) in the widely used ISO 15099 (2003) standard is based on data that does not extend into the range of box type windows. His main source, ElSherbiny did make measurements for $\mathrm{A}=10$ and 20 [-] that at least partially extended into the concerned zone, so did Yin et al. (1978). We also have the turbulent CFD results of Xaman et al. [35]. Most other authors concentrated their study on the flow regimes shown to be relevant for IG unity only.

We can compare the $\mathrm{Nu}$ number prediction of the various correlations for a given aspect ratio of $\mathrm{A}=20$ [-] by plotting them against one another in Fig. 15, and by comparing their $\%$ Error to the most widely used correlation of Wright $(\mathrm{Nu} /$ $\left.\mathrm{Nu}_{\text {Wright }}\right)$ in Fig. 16. The aspect ratio $\mathrm{A}=20[-]$ is chosen as a characteristic value for many box type windows, which is still at least in the vicinity of some IG units. All correlations start from $\mathrm{Nu}=1$ for the smallest Ra numbers based on theory, and they only start trending upwards between $\mathrm{Ra}=1 \mathrm{e} 3$ and $1 \mathrm{e} 4[-]$ where the convective heat transfer begins to express itself. For calculating IG units, this Ra region is the most important for the optimal sizing of the cavity thickness. A suboptimal thickness limits the useful convective heat transfer resistance of the cavity, while an above optimal thickness will result in an increased Nusselt number, which also limits the thermal resistance.

The different correlations give significantly different results for both intermediate (up to $10 \%$ difference for $\mathrm{Ra}=1 \mathrm{e} 3-2 \mathrm{e} 4$ ) and large Ra number flows ( $>20 \%$ difference for $\mathrm{Ra}>1 \mathrm{e} 5)$. The EN 673 (2011) and Yin et al. (1978) correlations give the most outlying results. For box type windows, the EN 673 (2011) correlation gives the largest $\mathrm{Nu}$ value followed by Wright, while all other sources report values that are smaller. ElSherbiny's correlation for $\mathrm{A}=20[-]$ is $10 \%$ while for Xaman et al. turbulent correlation are up to 20\% lower than Wright. Most of the other equations are not valid for such high Ra numbers and the EN 673 equation has no specified range of validity. Its lack of A dependence is another reason to mistrust it for cavities with $\mathrm{A}<40$.

ElSherbiny's data and independent correlations for $\mathrm{A}=5,10$ and 20 would be a good candidate to base our calculation for box type windows on, but as reported by Zhao (1998) they show an unphysical tendency for large Ra numbers. As described earlier, the Nu number should decrease with an increasing aspect ratio for any given $\mathrm{Ra}$ number as the top and bottom corners of the cavity (where the convection cell loops around) get further apart. The data of ElSherbiny shows the opposite trend indicating a possible measurement error. The turbulent CFD simulation of Xaman et al. [35] gives Nu numbers some 20\% smaller than Wright, but further study is needed to corroborate their findings. 
Table 1 Summary of correlations for the Nu number from the literature with their ranges of validity

\begin{tabular}{|c|c|c|c|c|c|c|}
\hline source & method & A & $\operatorname{Pr}$ & $\mathrm{Gr}$ & $\mathrm{Ra}$ & Correlation \\
\hline $\begin{array}{l}\text { Eckert and Carlson } \\
\text { (1961) }\end{array}$ & meas. & $\begin{array}{l}2.5- \\
46.7\end{array}$ & 0.71 & $\begin{array}{l}8 \mathrm{e} 4- \\
2 \mathrm{e} 5\end{array}$ & & $\begin{array}{l}\mathrm{Nu}=1+0.00166^{*} \mathrm{Gr}^{\wedge} 0.9 * \mathrm{~A} \text { (cod. r.) } \\
\mathrm{Nu}=0.119 * \mathrm{Gr}^{\wedge} 0.3^{*} \mathrm{~A}^{\wedge}-0.1 \text { (BL. r.) }\end{array}$ \\
\hline Jakob (1967) & meas. & $\begin{array}{l}3.12- \\
42.2\end{array}$ & 0.71 & $\begin{array}{l}2 \mathrm{e} 4- \\
2 \mathrm{e} 5\end{array}$ & & $\mathrm{Nu}=0.18 * \mathrm{Gr}^{\wedge} 0.25 * \mathrm{~A}^{\wedge}-0.111(2 \mathrm{e} 4<\mathrm{Gr}<2 \mathrm{e} 5)$ \\
\hline $\begin{array}{l}\text { Newell and } \\
\text { Schmidt (1970) }\end{array}$ & CFD & $2.5-20$ & 0.71 & $\begin{array}{l}4 \mathrm{e} 3- \\
1.4 \mathrm{e} 5\end{array}$ & & $\mathrm{Nu}=0.115 * \mathrm{Gr}^{\wedge} 0.315 * \mathrm{~A}^{\wedge}-0.265$ \\
\hline Yin et al. (1978) & meas. & $\begin{array}{l}4.9- \\
78.7\end{array}$ & 0.71 & $\begin{array}{l}1.5 \mathrm{e} 3- \\
7 \mathrm{e} 6\end{array}$ & & $\mathrm{Nu}=0.21 * \mathrm{Gr}^{\wedge} 0.269 * \mathrm{~A}^{\wedge}(-0.131)$ \\
\hline $\begin{array}{l}\text { Raithby and } \\
\text { Wong (1981) }\end{array}$ & CFD & $2-80$ & & & $\begin{array}{l}1 \mathrm{e} 3- \\
1 \mathrm{e} 5\end{array}$ & $\begin{array}{cl}\mathrm{Nu}=\left(1+\left(\left(0.344 \mathrm{Ra}^{* \wedge} 0.25\right) /\left(1+112 / \mathrm{Ra}^{* \wedge} 0.87\right)\right)^{\wedge} 2\right)^{\wedge} 0.5 \\
\text { where: } \mathrm{Ra}^{*}=(0.89-0.73 / \mathrm{A}) * \mathrm{Ra} / \mathrm{A} & \text { for adiabatic side walls } \\
\qquad \mathrm{Ra}^{*}=\left(1-1.02 / \mathrm{A}^{\wedge} 0.44\right)^{*} \mathrm{Ra} / \mathrm{A} & \text { for LTP side walls }\end{array}$ \\
\hline $\begin{array}{l}\text { ElSherbiny et al. } \\
\text { (1982b) }\end{array}$ & meas. & $5-110$ & & & $\begin{array}{l}1 \mathrm{e} 2- \\
2 \mathrm{e} 7\end{array}$ & $\begin{array}{l}\mathrm{Nu}(\mathrm{A}=5)=\max \left(\left(1+\left(0.193 \mathrm{Ra}^{\wedge} 0.25 /\left(1+(1800 / \mathrm{Ra})^{\wedge} 1.289\right)\right)^{\wedge} 3\right)^{\wedge} 1 . / 3\right. \\
\left.0.0605 * \mathrm{Ra}^{\wedge} 1 / 3\right) \\
\mathrm{Nu}(\mathrm{A}=10)=\max \left(\left(1+\left(0.125 \mathrm{Ra}^{\wedge} 0.28\right)^{\wedge} 9\right)^{\wedge} 1 / 9 ; 0.061 \mathrm{Ra}^{\wedge} 1 / 3\right) \\
\mathrm{Nu}(\mathrm{A}=20)=\left(1+\left(0.064 \mathrm{Ra}^{\wedge} 1 / 3\right)^{\wedge} 6.5\right)^{\wedge} 1 / 6.5 \\
\mathrm{Nu}(\mathrm{A}=40)=\left(1+\left(0.0303 \mathrm{Ra}^{\wedge} 0.402\right)^{\wedge} 11\right)^{\wedge} 1 / 11 \\
\mathrm{Nu}(\mathrm{A}=80)=\left(1+\left(0.0227 \mathrm{Ra}^{\wedge} 0.438\right)^{\wedge} 18\right)^{\wedge} 1 / 18 \\
\mathrm{Nu}(\mathrm{A}=100)=\left(1+\left(0.0607 \mathrm{Ra}^{\wedge} 1 / 3\right)^{\wedge} 18\right)^{\wedge} 18 \\
\mathrm{Nu} 1=0.0605 * \mathrm{Ra}^{\wedge} 1 / 3 \\
\mathrm{Nu} 2=\left(1+\left(0.104 \mathrm{Ra}{ }^{\wedge} 0.293 /\left(1+(6310 / \mathrm{Ra})^{\wedge} 1.36\right)\right)^{\wedge} 3\right)^{\wedge} 1 / 3 \\
\mathrm{Nu} 3=0.242 *(\mathrm{Ra} / \mathrm{A})^{\wedge} 0.272 \\
\mathrm{Nu}=\max (\mathrm{Nu} 1, \mathrm{Nu} 2, \mathrm{Nu} 3)\end{array}$ \\
\hline $\begin{array}{l}\text { Shewen } \\
\text { et al. (1996) }\end{array}$ & meas. & $>40$ & & & $<1 \mathrm{e} 6$ & $\mathrm{Nu}=\left(1+\left(0.0665 \mathrm{Ra}^{\wedge} 1 / 3 /\left(1+(9000 / \mathrm{Ra})^{\wedge} 1 / 7\right)\right)^{\wedge} 2\right)^{\wedge} 1 / 2$ \\
\hline Zhao (1998) & CFD & $5-110$ & & & $<2 \mathrm{e} 4$ & $\begin{array}{l}\mathrm{Nu} 1=\left(1+\left(\left(0.788335^{*} \mathrm{~B}^{\wedge} 0.881073\right) /\left(139.677+\mathrm{B}^{\wedge} 0.724505\right)\right)^{\wedge} 2\right)^{\wedge} 0.5 \\
\mathrm{~B}=(1.42227-1.41845 / \mathrm{A}) * \mathrm{Ra} / \mathrm{A} \quad(\mathrm{A}=5-30) \\
\mathrm{Nu} 2=\left(1+0.00044265^{*}(\mathrm{Ra} / \mathrm{A})^{\wedge} 1.36869\right)^{\wedge} 0.326071 \quad(\mathrm{~A}=30-110)\end{array}$ \\
\hline Power (1999) & CFD & $20-60$ & & & $\sim \mathrm{A}$ & $\begin{aligned} \mathrm{Nu}=0.1098 *\left(\mathrm{Ra}^{\wedge} 1 / 2 * \mathrm{~A}^{\wedge}-1 / 6\right)^{\wedge} 0.6113 & (\mathrm{~A}=203.5 \mathrm{e} 4<\mathrm{Ra}<5.25 \mathrm{e} 5) \\
& (\mathrm{A}=303 \mathrm{e} 4<\mathrm{Ra}<4.06 \mathrm{e} 5) \\
& (\mathrm{A}=401 \mathrm{e} 4<\mathrm{Ra}<1.7 \mathrm{e} 5) \\
& (\mathrm{A}=501 \mathrm{e} 4<\mathrm{Ra}<1 \mathrm{e} 5) \\
& (\mathrm{A}=602 \mathrm{e} 4<\mathrm{Ra}<4.4 \mathrm{e} 4)\end{aligned}$ \\
\hline Yang (2003) & CFD & $20-100$ & & & $2 \mathrm{e} 4-2 \mathrm{e} 5$ & $\mathrm{Nu}=\left(0.0979573 * \mathrm{Ra}^{\wedge} 0.310338\right) /\left(\mathrm{A}^{\wedge} 0.0860783\right)$ \\
\hline $\begin{array}{l}\text { Xaman et al. } \\
(2005)\end{array}$ & CFD & $\begin{array}{l}20,40 \\
80\end{array}$ & & & $1 \mathrm{e} 3-1 \mathrm{e} 8$ & $\begin{array}{ll}\text { laminar }(\mathrm{Ra}=1 \mathrm{e} 3-1 \mathrm{e} 6): & \\
\mathrm{Nu}=0.1731 \mathrm{Ra}^{\wedge} 0.2617 & (\mathrm{~A}=20) \\
\mathrm{Nu}=0.1865 \mathrm{Ra}^{\wedge} 0.245 & (\mathrm{~A}=40) \\
\mathrm{Nu}=0.1897 \mathrm{Ra}^{\wedge} 0.2398 & (\mathrm{~A}=80) \\
\text { turbulent }(\mathrm{Ra}=1 \mathrm{e} 4-1 \mathrm{e} 8): & \\
\mathrm{Nu}=0.0857 \mathrm{Ra}^{\wedge} 0.3033 & (\mathrm{~A}=20) \\
\mathrm{Nu}=0.0635 \mathrm{Ra}^{\wedge} 0.323 & (\mathrm{~A}=40) \\
\mathrm{Nu}=0.054 \mathrm{Ra}^{\wedge} 0.3333 & (\mathrm{~A}=80)\end{array}$ \\
\hline EN 673 (2011) & - & & & & & $\begin{array}{ll}\mathrm{Nu}=0.035^{*}(\mathrm{Gr} * \operatorname{Pr})^{\wedge} 0.38 & \left(\varphi=90^{\circ} \text { or vertical or vertical }\right) \\
\mathrm{Nu}=0.1 *(\mathrm{Gr} * \operatorname{Pr})^{\wedge} 0.31 & \left(\varphi=45^{\circ}\right) \\
\mathrm{Nu}=0.16^{*}(\mathrm{Gr} * \operatorname{Pr})^{\wedge} 0.28 & \left(\varphi=0^{\circ} \text { or horizontal }\right)\end{array}$ \\
\hline
\end{tabular}



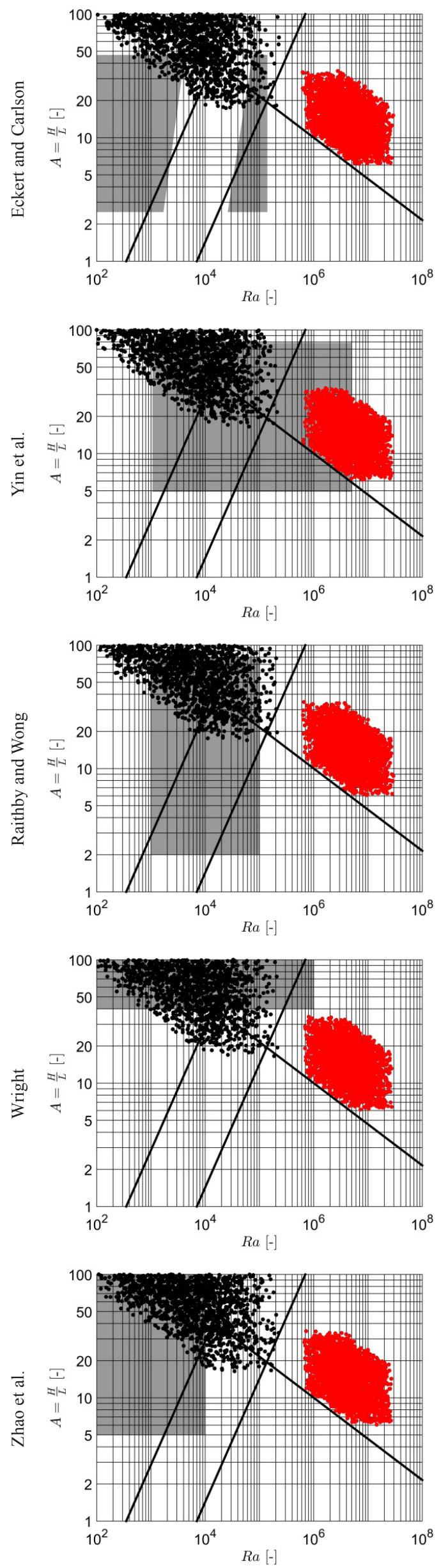
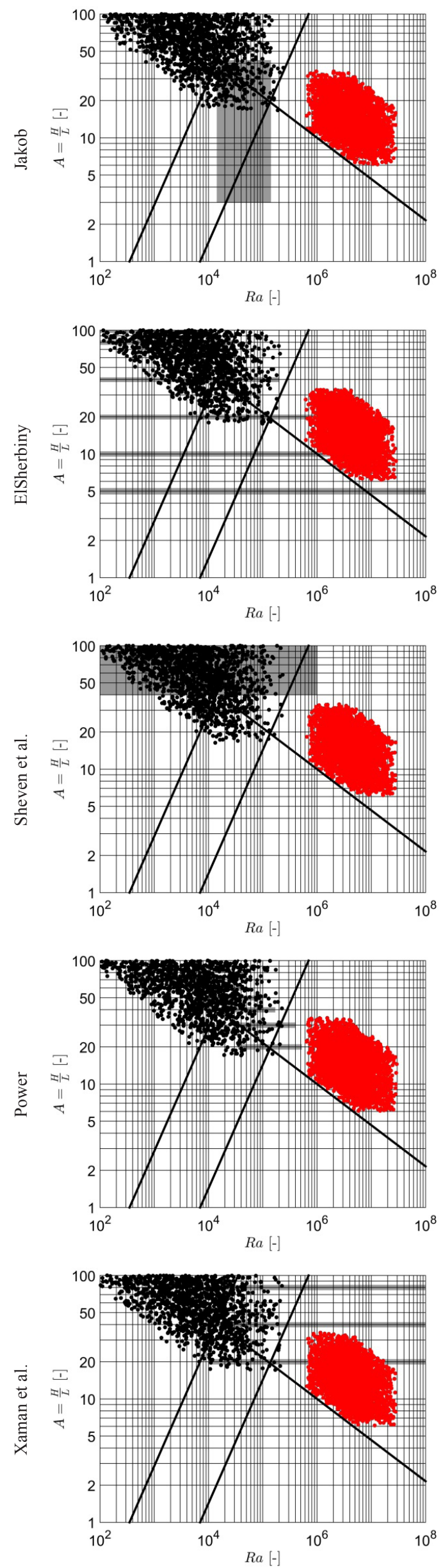

Fig. 14 A comparison of the range of validity for various $\mathrm{Nu}$ correlations as published by their authors 


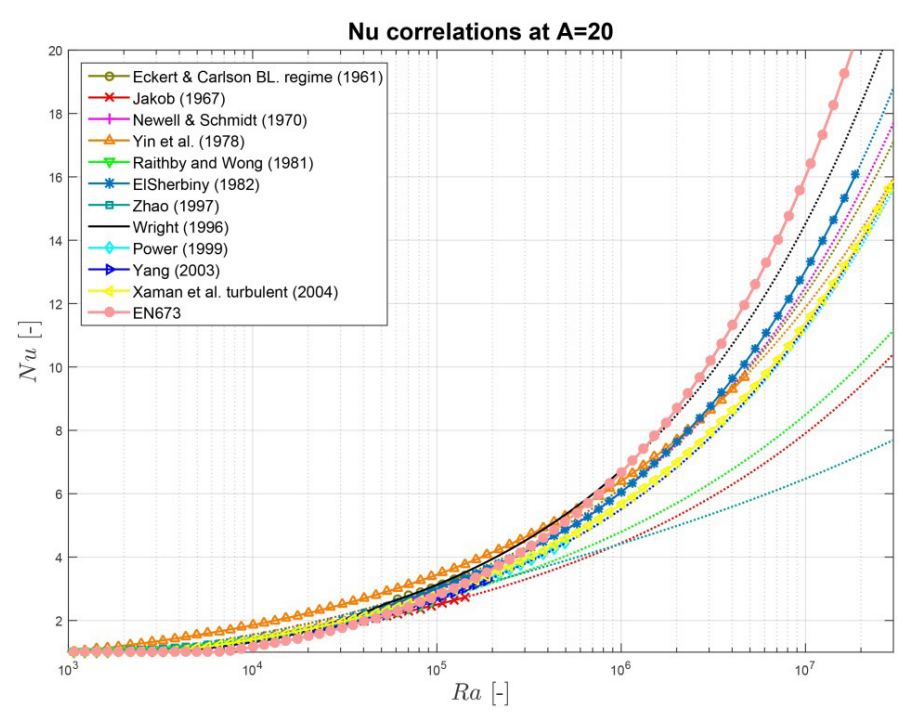

Fig. 15 A comparison of the different $\mathrm{Nu}$ correlations for $\mathrm{A}=20[-]$

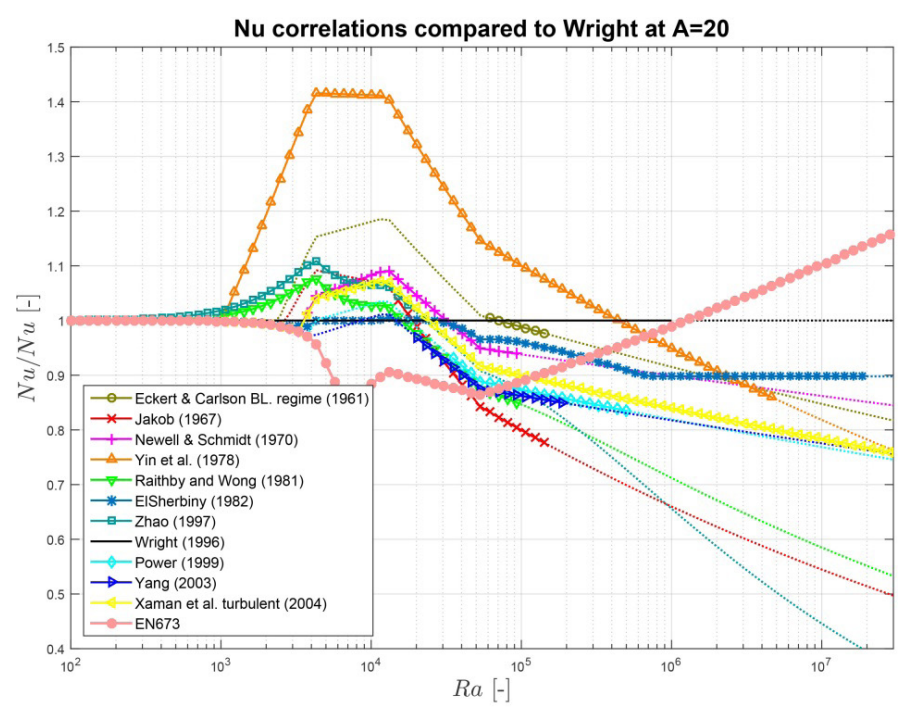

Fig. 16 A comparison of the different Nu correlations for $\mathrm{A}=20[-]$ to the correlation of Wright / ISO15099

\section{Conclusions}

The different cavity dimensions of Box type windows were shown to result in a type of natural convection very different from the one encountered in the much thinner cavities of insulating glass units. The literature review of publications on flow characterization and convective heat transfer calculations, which serve as a basis for most contemporary fenestration heat transfer calculation tools, reveals their understandable bias towards the geometry and Rayleigh number range of IG units - a flow regime with very different characteristics. As a consequence, the analysis of published Nusselt number correlations shows few equations that are useful for box type windows, with very large discrepancies in their predictions. The correlations in the most commonly used standards EN 673 and ISO 15099, both seem inadequate due to their neglect of the cavity aspect ratio as an influencing parameter, the fact that box type windows lie outside their published area of validity and their disagreement with more recent results. Based on the available literature alone, no definitive statement can be made on which correlation is the best suited for box type windows. Further study is needed focusing directly on the flow regime of such windows to generate a new dedicated correlation and to investigate the other effects the difference of box type windows' might have on the accuracy of fenestration thermal calculation tools.

\section{References}

Bakonyi, D., Becker, G. (2014) Possibilities of simulations in the planning of the retrofit of historical double skin windows. Advanced Materials Research. 899, pp. 155-160.

DOI: 10.4028/www.scientific.net/AMR.899.155

Batchelor, G. K. (1954) Heat transfer by free convection across a closed cavity between vertical boundaries at different temperatures. Quarterly of Applied Mathematics. 12(3), pp. 209-233.

Blanusa, P., Goss, W. P., Roth, H., Weitzmann, P., Jensen, C. F., Svendsen, S., Elmahdy, H. (2007) Comparison between ASHRAE and ISO thermal transmittance calculation methods. Energy and Buildings. 39(3), pp. 374-384. DOI: 10.1016/j.enbuild.2006.09.007

Eckert, E. R. G., Carlson, W. O. (1961) Natural convection in an air layer enclosed between two vertical plates with different temperatures. International Journal of Heat and Mass Transfer. 2(1-2), pp. 106-120. DOI: 10.1016/0017-9310(61)90019-9

Elder, J. W. (1965) Laminar free convection in a vertical slot. Journal of Fluid Mechanics, 23(1), pp. 77-98. DOI: 10.1017/S0022112065001246

ElSherbiny, S. M., Hollands, K. G. T., Raithby, G. D. (1982) Effect of thermal boundary conditions on natural convection in vertical and inclined air layers. Journal of Heat Transfer. 104(3), pp. 515-520.

DOI: $10.1115 / 1.3245123$

ElSherbiny, S., Hollands, K., Raithby, G. (1982) Effect of the Thermal Boundary Condition on Natural Convection in Vertical and Inclined Air Layers. Transaction of the ASME. July 27-30, 1982. pp. 96-102.

EN 673 - Glass in building. Determination of thermal transmittance (U value). Calculation method. (2011)

EN 10077-1 - Thermal performance of windows, doors and shutters. Calculation of thermal transmittance - Part 1: General (2006)

EN 10077-2 - Thermal performance of windows, doors and shutters. Calculation of thermal transmittance - Part 2: Numerical method for frames. (2012)

EN 410 - Glass in building. Determination of luminous and solar characteristics of glazing. (2011)

Gustavsen, A., Arasteh, D., Jelle, B. P., Curcija, C., Kohler, C. (2008) Developing Low-Conductance Window Frames: Capabilities and Limitations of Current Window Heat Transfer Design Tools - State-of-the-Art Review. Journal of Building Physics. 32(2), pp. 131-153.

DOI: $10.1177 / 1744259108097672$

Hollands, K. G. T., Unny, T. E., Raithby, G. D., Konicek, L. (1976) Free Convective Heat Transfer Across Inclined Air Layers. Journal of Heat Transfer. 98(2), pp. 189-193. DOI: 10.1115/1.3450517

Ince, N. Z., Launder, B. E. (1989) On the computation of buoyancy driven turbulent flows in rectangular enclosures. International Journal of Heat and Fluid Flow. 10(2), pp. 110-117. DOI: 10.1016/0142-727X(89)90003-9

ISO 9050 - Glass in building. Determination of light transmittance, solar direct transmittance, total solar energy transmittance, ultraviolet transmittance and related glazing factors. (2003) 
ISO 10292 - Glass in building. Calculation of steady-state U values (thermal transmittance) of multiple glazing. (1994)

ISO 15099 - Thermal performance of windows, doors and shading devices Detailed calculations. (2003)

Jakob, M. (1967) Journal of Heat Transfer, 1, pp. 536-539.

Klems, J. H. (1994) A New Method for Predicting the Solar Heat Gain of Complex Fenestration Systems - I. Overview and Derivation of the Matrix Layer Calculation. ASHRAE Transactions. 100(1), pp. 1065-1072.

Klems, J. H. (1994) A New Method for Predicting the Solar Heat Gain of Complex Fenestration Systems - II. Detailed Description of the Matrix Layer Calculation. ASHRAE Transactions. 100(1), pp. 1073-1086.

Kumar, S. (2010) Investigation of 3D Heat Transfer Effects in Fenestration Products. MSc Thesis, University of Massachusetts Amherst.

Lawrence Berkeley National Laboratory: Window 7.3

Lee, Y., Korpela, S. A. (1983) Multicellular Natural Convection in a Vertical Slot. Journal of Fluid Mechanics. 126, pp. 91-121. DOI: $10.1017 / \mathrm{S} 0022112083000063$

Newell, M. E., Schmidt, F. W. (1970) Heat Transfer by Laminar Natural Convection Within Rectangular Enclosures. Journal of Heat Transfer. 92(1), pp. 159-167. DOI: $10.1115 / 1.3449616$

NFRC 100-2010 - Procedure for Determining Fenestration Product U-factors. (2010)

Power, J. P. (1999) Finite Element Model of Turbulent Flow and Heat Transfer in a FenestrationSystem. PhD Thesis, Department of Mechanical Engineering, University of Massachusetts Amherst.

Raithby, G. D., Wong, H. H. (1981) Heat transfer by natural convection across vertical air layers. Numerical Heat Transfer. 4(4), pp. 447-457. DOI: $10.1080 / 01495728108961803$

Shewen, E. C., Hollands, K. G. T., Raithby, G. D. (1989) The Measurement of Surface Heat Flux Using the Peltier Effect. Journal of Heat Transfer. 111(3), pp. 798-803. DOI: 10.1115/1.3250754
Shewen, E., Hollands, K. G. T., Raithby, G. D. (1996) Heat Transfer by Natural Convection Across a Vertical Air Cavity of Large Aspect Ratio. Journal of Heat Transfer. 118(4), pp. 993-995. DOI: 10.1115/1.2822603

Wright, J. L., Sullivan, H. F. (1989) Natural Convection in Sealed Glazing Units: A Review. ASHRAE Transactions. 95(1), pp. 592-603.

Wright, J. L. (1996) A Correlation to Quantify Convective Heat Transfer Between Vertical Window Glazings. ASHRAE Transactions. 102, pp. 940-946.

Wright, J. L. (1998) A Simplified Numerical Method for Assessing the Condensation Resistance of Windows. ASHRAE Transactions. 104(1), pp. 1222-1229.

Xaman, J., Álvarez, G., Lira, L., Estrada, C. (2005) Numerical study of heat transfer by laminar and turbulent natural convection in tall cavities of façade elements. Energy and Buildings. 37(7), pp. 787-794. DOI: 10.1016/j.enbuild.2004.11.001

Yang, Y. (2003) Natural convection flow and heat transfer in vertical and inclined glazing cavities. MSc Dissertation, Department of Mechanical and Industrial Engineering, University of Massachusetts Amherst.

Yin, S. H., Wung, T. Y., Chen, K. (1978) Natural convection in an air layer enclosed with rectangular cavities. International Journal of Heat and Mass Transfer. 21(3), pp. 307-315. DOI: 10.1016/0017-9310(78)90123-0

Zhao, Y., Goss, W., Curcija, D., Power, J. (1998) Improved Heat Transfer Correlations for Quantifying Laminar Natural Convection Across Fenestration Glazing Cavities. In: Thermal Envelopes VII, Clearwater, Florida, December 1998, pp. 397-403.

Zhao, Y., Goss, W. P., Curcija, D. (1997) Prediction the Multicellular Flow Regime of Natural Convection in Fenestration Glazing Cavities. ASHRAE Transactions. 103(1), pp. 1009-1020. 